\title{
Radiation-induced nausea and vomiting: A comparison between MASCC/ESMO, ASCO and NCCN antiemetic guidelines
}

Erin McKenzie, Pearl Zaki, Srinivas Raman, Robert Olson, Thomas McFarlane, Carlo DeAngelis, Stephanie Chan, William Pidduck, Yasmeen Razvi, Ahmad Bushehri, Edward Chow

Odette Cancer Centre, Sunnybrook Health Sciences Centre,

University of Toronto, Toronto, ON, Canada

A Sunnybrook

is

Introduction

Radiation-induced nausea and vomiting (RINV) can affect $50-80 \%$ of patients undergoing radiotherapy (RT) and negatively impacts quality of life (QOL).

Medications known as antiemetics are given either prophylactically or as rescue therapy to treat nausea and vomiting.

The principal constituent of RINV antiemetic regimens is the 5-HT3 receptor antagonist (5-HT3 RA), although dexamethasone (DEX), dopamine receptor antagonists (DRA) can be prescribed.

This review compared RINV antiemetic guidelines produced by MASCC/ESMO, ASCO and NCCN and discussed guideline updates.

\section{Methods}

A thorough examination of the published antiemetic guidelines for each organization was performed. Guideline changes within each organization from the previous publication to the recent update and key studies to support these changes were identified. Similarities and differences between guidelines were identified and key areas of dissension were discussed.

\section{Results}

Levels of Emetogenic Risk

MASCC/ESMO, ASCO, and NCCN use a common risk classification to describe the typical incidence of RINV based on location of RT.

Table 1 shows level of emetogenic risk

\section{Key Updates}

MASCC/ESMO:

Craniospinal region should receive prophylaxis with a 5-HT3 RA and optional DEX.

Low and minimal risk RT regimens can use DEX or DRAs in addition to 5-HT3 RAs.

ASCO:

Recommended 5-HT3 RAs were narrowed to prefer granisetron and ondansetron, with tropisetron for moderate risk regimens.

DEX recommended to follow the course of the 5-HT3 RA for high-risk regimens rather than solely for the first 5 fractions.

Treatment recommendations for low- and minimal-risk categories were extended to include DEX, 5-HT3 RAs or DRAs as rescue therapy only

NCCN did not change its guidelines from the previous 2015 publication

Table 2 displays the comparison between published antiemetic guidelines

Table 2: Comparison between MASCC/ESMO, ASCO, NCCN antiemetic guidelines

\begin{tabular}{|c|c|c|c|}
\hline Risk Category & MASCC/ESMO 2016 & ASCO 2017 & NCCN 2017 \\
\hline High & $\begin{array}{l}\text { Prophylaxis with a } 5 \mathrm{HT} 3 \mathrm{RA} \\
\text { and DEX }\end{array}$ & $\begin{array}{l}\text { Prophylaxis with a 5HT3 RA } \\
\text { (granisetron, ondansetron) and } \\
\text { DEX daily }\end{array}$ & $\begin{array}{l}\text { Prophylaxis with a 5HT3 RA } \\
\text { (granisetron, ondansetron) and } \\
\text { optional DEX daily }\end{array}$ \\
\hline Moderate & $\begin{array}{l}\text { Prophylaxis with a } 5 \mathrm{HT} 3 \mathrm{RA} \\
\text { and optional DEX }\end{array}$ & $\begin{array}{l}\text { Prophylaxis with a } 5 \mathrm{HT} 3 \mathrm{RA} \\
\text { (granisetron, ondansetron, } \\
\text { tropisetron) and optional DEX for } \\
\text { the first five fractions }\end{array}$ & $\begin{array}{l}\text { Prophylaxis with a } 5 \mathrm{HT} 3 \mathrm{RA} \\
\text { (granisetron, ondansetron) and } \\
\text { optional DEX daily }\end{array}$ \\
\hline Low & $\begin{array}{l}\text { Prophylaxis or rescue with a } \\
5 \text { HT3 RA, DRA or DEX } \\
\text { Cranium - prophylaxis or } \\
\text { rescue with DEX }\end{array}$ & $\begin{array}{l}\text { Rescue with a 5HT3 RA } \\
\text { (granisetron, ondansetron), DRA } \\
\text { (prochlorperazine, } \\
\text { metoclopramide), or DEX } \\
\text { Cranium - rescue with DEX }\end{array}$ & None \\
\hline Minimal & $\begin{array}{l}\text { Rescue with a } 5 \mathrm{HT} 3 \mathrm{RA} \text {, } \\
\text { DRA or DEX }\end{array}$ & $\begin{array}{l}\text { Rescue with a 5HT3 RA } \\
\text { (granisetron, ondansetron), DRA } \\
\text { (prochlorperazine, } \\
\text { metoclopramide), or DEX }\end{array}$ & None \\
\hline \multicolumn{4}{|l|}{ Special Considerations } \\
\hline $\begin{array}{l}\text { Concomitant } \\
\text { Chemotherapy }\end{array}$ & \multicolumn{3}{|c|}{$\begin{array}{l}\text { Antiemetic prophylaxis should follow the guidelines for CINV regimens. If emetic risk of RT is higher than } \\
\text { that of the concomitant CT, then the risk level of RT must be chosen to tailor the antiemetic treatment. }\end{array}$} \\
\hline Breakthrough Emesis & None & None & $\begin{array}{l}\text { Patients who experience } \\
\text { breakthrough nausea and/or vomiting } \\
\text { may be treated with a different class } \\
\text { of agent, or with ondansetron or } \\
\text { granisetron if they did not receive } \\
\text { primary prophylaxis }\end{array}$ \\
\hline
\end{tabular}

$\mathrm{CT}$ = chemotherapy, $\mathrm{RT}$ = radiotherapy, $\mathrm{CRT}$ = chemotherapy and radiotherapy, 5HT3 RA = serotonin receptor antagonist $\mathrm{DRA}=$ dopamine receptor antagonist, DEX = dexamethasone, CINV = chemotherapy-induced nausea and vomiting

\section{Discussion and Conclusions}

The guidelines suggest prophylaxis with a 5-HT3 RA and DEX in the high-risk category and rescue with 5-HT3 RA, DEX or DRA. Recommendations for moderate- and low-risk categories display more variability between organizations.

The variability in RINV study design limits the generalizability of results and leads to inconsistencies in recommendations.

There is no distinction between treatment of nausea and vomiting in RINV guidelines despite the inferior complete control rates of nausea compared to vomiting and nausea is often underestimated by physicians or underreported by patients.

There are few studies that examine low- and minimal-risk categories, leading to contradictory guideline recommendations.

Novel drugs studied in the chemotherapy setting, such as palonosetron and olanzapine, could be effectively used in RINV treatment regimens for superior control in the delayed phase of RINV.

Adherence to RINV guidelines is lowest in moderate- and low-risk regimens and practice patterns vary internationally.

Future studies should investigate the distinct role of nausea in RINV, the use of CINV antiemetics for RINV and include a standardized study design to improve guideline recommendations and optimize patient QOL. 